\title{
Facticidade e diferença: elementos de filosofia da linguagem e filosofia do direito
} em habermas e derrida

\section{Facticity and difference: elements of philosophy of language and philosophy of law in habermas and derrida}

DOI: $10.46814 / \operatorname{lajdv3n1-022}$

Recebimento dos originais: 30/10/2020

Aceitação para publicação: 23/12/2020

\author{
Lucas Antonio Saran \\ Pontifícia Universidade Católica (Doutorando) \\ E-mail: lucasasaran@gmail.com
}

Rogério Cangussu Dantas Cachichi

Mestre em direito pelo Centro Universitário Eurípedes de Marília

E-mail: rogeriocangussu@gmail.com

\section{RESUMO}

Dutra (2013) chama atenção para o fato de que há um claro ponto de discordância entre Habermas e Derrida. Com certeza, Dutra possui razão em sua postura, e, muito provavelmente, uma consulta direta a Habermas acabaria por confirmar a discordância do filosofo alemão com relação ao filósofo francês (Derrida). Apesar disso, esta comunicação possui a pretensão de realizar um esboço de aproximação entre Habermas e Derrida. Deveras, analisadas separadamente a estrutura das reflexões gerais de ambos os autores, observar-se-á que, ao final, a despeito das discordâncias, o filósofo da ação comunicativa e o filósofo da différance possuem, inexoravelmente, pontos de similaridade. Este modesto projeto de correlação entre Habermas e Derrida nasce delimitado pelos campos da filosofia do direito e da filosofia da linguagem. Nessa toada, o texto encontra-se dividido em três momentos centrais: primeiro, alguns elementos do pensamento de Habermas (filosofia da linguagem, facticidade, validade etc) são consignados, especialmente a configuração da modernidade a partir da dualidade entre os sistemas e o mundo da vida, apresentando-se o direito como importante elementos de mediação. Na sequência, focam-se Derrida e suas reflexões sobre a filosofia da linguagem e a filosofia do direito, sobretudo no particular crítica à metafísica da presença levada a efeito em duas importantes obras desse autor, a saber, Gramatologia e Força de lei. Ao final, os dois autores são objeto de aproximação e, como prometido, são apresentadas certas relações entre ambos. Pedimos que nossos leitores entendam que o objetivo nesse desenvolvimento não é desconsiderar as idiossincrasias dos dois autores estudados, mas mostrar que, por assim dizer, não deixa, também, de existir consenso entre eles. Acreditamos que esse tipo de trabalho é lícito e importante: por vezes, tanto os filósofos, quando seus admiradores tomam uma postura demasiado combativa e destrutiva; acreditamos ser uma possível função do historiador da filosofia mostrar até que ponto tal postura (combativa) é razoável e lícita.

Palavras-Chave: Habermas, Derrida, Linguagem, Direito.

\section{ABSTRACT}

Dutra (2013) calls attention to the fact that there is a clear point of disagreement between Habermas and Derrida. Dutra is certainly right in his attitude, and a direct consultation with Habermas would most likely confirm the disagreement of the German philosopher with the French philosopher (Derrida). Nevertheless, this communication has the pretension of making an approximation between Habermas and Derrida. In fact, when the structure of the general reflections of both authors is analyzed 
separately, it will be observed that, in the end, despite the disagreements, the philosopher of communicative action and the philosopher of différance have, inexorably, points of similarity. This modest project of correlation between Habermas and Derrida is born delimited by the fields of philosophy of law and philosophy of language. The text is divided in three central moments: first, some elements of Habermas' thought (philosophy of language, factuality, validity, etc.) are consigned, especially the configuration of modernity from the duality between the systems and the world of life, presenting law as an important element of mediation. Derrida and his reflections on the philosophy of language and the philosophy of law, especially on the particular criticism of the metaphysics of the presence carried out in two important works of this author, namely, Gramatology and Law Enforcement. In the end, the two authors are the object of approximation and, as promised, certain relationships between them are presented. We ask our readers to understand that the objective in this development is not to disregard the idiosyncrasies of the two authors studied, but to show that, so to speak, there is also consensus between them. We believe that this kind of work is licit and important: sometimes both philosophers and their admirers take too combative and destructive a posture; we believe that it is a possible function of the historian of philosophy to show to what extent such a (combative) posture is reasonable and licit.

Keywords: Habermas, Derrida, Language, Law.

\section{INTRODUÇÃO}

Dutra (2013) chama atenção para o fato de que há um claro ponto de discordância entre Habermas e Derrida. Com certeza, Dutra possui razão em sua postura, e, muito provavelmente, uma consulta direta a Habermas acabaria por confirmar a discordância do filosofo alemão com relação ao filósofo francês (Derrida).

Apesar disso, esta comunicação possui a pretensão de realizar um esboço de aproximação entre Habermas e Derrida. Deveras, analisadas separadamente a estrutura das reflexões gerais de ambos os autores, observar-se-á que, ao final, a despeito das discordâncias, o filósofo da ação comunicativa e o filósofo da différance possuem, inexoravelmente, pontos de similaridade.

Este modesto projeto de correlação entre Habermas e Derrida nasce delimitado pelos campos da filosofia do direito e da filosofia da linguagem. Nessa toada, o texto encontra-se dividido em três momentos centrais: primeiro, alguns elementos do pensamento de Habermas (filosofia da linguagem, facticidade, validade etc) são consignados; depois, focam-se Derrida e suas reflexões sobre a filosofia da linguagem e a filosofia do direito; ao final, os dois autores são objeto de aproximação e, como prometido, são apresentadas certas relações entre ambos.

Pedimos que nossos leitores entendam que o objetivo nesse desenvolvimento não é desconsiderar as idiossincrasias dos dois autores estudados, mas mostrar que, por assim dizer, não deixa, também, de existir consenso entre eles. Acreditamos que esse tipo de trabalho é lícito e importante: por vezes, tanto os filósofos, quando seus admiradores tomam uma postura demasiado 
combativa e destrutiva; acreditamos ser uma possível função do historiador da filosofia mostrar até que ponto tal postura (combativa) é razoável e lícita.

\section{MODERNIDADE, RACIONALIZAÇÃO, FACTICIDADE E VALIDADE: BREVE INTERCURSO PELO PENSAMENTO DE HABERMAS}

Na condição de assistente de Adorno, "Habermas leu a Dialética do Esclarecimento de Adorno e Horkheimer já em 1953. Nesta obra de 1947, que teve uma grande influência, os dois autores tinham como objetivo, entre outros, mostrar como o Esclarecimento, entendido como filosofia da razão, se tinha transformado no seu contrário, isto é, em irracionalidade e autodestruição" (PINZANI, 2009, p.19). Como reconheceram Adorno e Horkheimer, o próprio esclarecimento não deixou de ser um mito na modernidade (BANNWART JÚNIOR, 2008, p.72).

Diante disso, viu-se Habermas motivado a repensar a modernidade. Para tanto, partiu do diagnóstico de Max Weber para quem o que caracteriza a modernidade foi um processo de desacoplamento entre mundo da vida e sistemas. Para Weber a modernidade está caracterizada por um processo de racionalização. A modernidade veio ao lume com uma promessa: libertar os homens do julgo da religião. Essa é a promessa (não cumprida) da modernidade. O ethos é substituído pela razão e a teleologia pela imparcialidade. A ética é baseada pelo sujeito, com pretensão de universalidade. Diz Habermas:

Max Weber introduziu o conceito de "racionalidade" para definir a forma da atividade econômica capitalista, do tráfego social regido pelo direito privado burguês e da dominação burocrática. Racionalização significa, em primeiro lugar, a ampliação das esferas sociais, que ficam submetidas aos critérios de decisão racional. (HABERMAS, 1968, p.45)

Essa racionalização incide no quadro institucional que no período medieval era composto de elementos: cultura, sociedade, personalidade, tudo sob a base da religião. Com a racionalização, sai de cena a religião; os saberes (direito, ciência, técnica, ética, moral, política, economia, estado) miram para fora do quadro institucional (mundo da vida), inaugurando racionalidades próprias.

Houve uma perda de sentido no mundo da vida. A razão se partiu em várias razões. Esse desacoplamento entre sistemas e mundo da vida é o que caracteriza a modernidade. Com efeito, nesse processo de racionalizar as esferas de produção do saber migraram de dentro do mundo da vida (onde se encontravam fundadas na religião) para fora, criando sistemas dotados de racionalidade própria.

Dentro do mundo da vida, houve um processo de racionalização da cultura, da sociedade e da personalidade, que deixaram de ser fulcrados na religião. Habermas chamou esse processo de descentralização, e não de desacoplamento. O conceito de descentralização é tomado por Habermas a partir de Piaget (BANNWART JÚNIOR, 2008, p. 54). 
Como se vê, Habermas enxerga a sociedade de modo dual: de um lado as esferas ligadas à produção do saber; de outro, as esferas ligadas ao modo pelo qual os indivíduos dão sentido à sua existência. Essa última é o mundo da vida propriamente dito, que possui três elementos: cultura, sociedade e personalidade agora sem base na religião. Os sistemas, externos ao mundo da vida, passam a ter racionalidades próprias. O problema, como destacou Pinzani, é que "na sociedade atual (...) o mundo da vida corre o risco de ser 'colonizado' pelos sistemas da economia e da administração - e isso leva a uma corrosão dos âmbitos de ação estruturados em termos comunicativos" (2009, p.98). As interações sociais perpassam prioritariamente não por valores ou normas, mas por dinheiro e poder administrativo:

\footnotetext{
Sociedades modernas são integradas não somente através de valores, normas e processos de entendimento, mas também sistemicamente, através de mercados e do poder administrativo. Dinheiro e poder administrativo constituem mecanismos da integração social, formadores de sistema, que coordenam as ações de forma objetiva, como que por trás das costas dos participantes da interação, portanto não necessariamente através da sua consciência intencional ou comunicativa. (HABERMAS, 1997, p.61)
}

Põe-se em questão como a moral secularizada poderá subsistir (PINZANI, 2009, p.107). Nessa empresa, Habermas não vê alternativa senão a necessidade de reabilitar a razão prática, a fim de que a razão comunicativa, não a instrumental, assuma sua função de governar as relações entre seres humanos, produzindo agir comunicativo, não instrumental. O agir comunicativo difere do agir instrumental na medida em que o primeiro orienta-se pelo entendimento; o segundo pela manipulação dentro do binômio meio-fim. "Somente essa racionalidade comunicativa permite, porém, uma resistência eficaz contra a colonização do mundo da vida por parte dos subsistemas" (PINZANI, 2009, p.111). Habermas escreveu: "O conceito do agir comunicativo atribui as forças ilocucionárias da linguagem orientada ao entendimento a função importante da coordenação da ação" (1997, p.25).

Isso implica a rejeição de soluções monologicamente estabelecidas, mas "exigem esforço de cooperação", porquanto, "ao entrarem numa argumentação moral, os participantes prosseguem seu agir comunicativo numa atitude reflexiva co o objetivo de restaurar um consenso perturbado" (HABERMAS, 2003, p.87). Diversamente das ações estratégicas - direcionadas a um fim -, a ação comunicativa são orientadas pelo consenso, de modo que a moral agora secularizada - antes baseada na religião - obtém arrimo no entendimento, na linguagem.

A relação entre facticidade e validade após a guinada linguística apresenta-se mergulhada na linguagem e em seu uso pela comunidade de falantes (linguagem ordinária do mundo da vida). Segundo Habermas, "...a tensão entre ideia e realidade irrompe na própria facticidade de formas de vida estruturadas liguisticamente" (1997, p.21), de tal modo que "a teoria do agir comunicativo tenta assimilar a tensão que existe entre facticidade e validade"(1997, p.25). 
Nesse quadro, o direito assume papel importante, cabendo-lhe tripla função. Pinzani nos ensina:

Ele é, em primeiro lugar, um espaço de mediação entre facticidade e validade(...). Em segundo lugar, ele é meio de integração social que é ameaçada pela mediação entre mundo da vida e sistemas parciais. Finalmente, ele é meio de uma integração social que já não pode ser alcançada por forças morais. Deste último ponto de vista, o direito contempla ou até substitui a moral. (2009, p.145)

E de fato, logo nos capítulos iniciais de Direito e Democracia, Habermas deixa claro que procura "atingir um duplo fim: esclarecer por que a teoria do agir comunicativo concede um valor posicional central à categoria do direito e por que ela mesma forma, por seu turno, um contexto apropriado para uma teoria do direito apoiada no princípio do discurso" (1997, p.24). E, de fato, como acentuou Durão:

...o direito funciona como transformador linguístico, traduzindo a linguagem estratégica dos
sistemas para a linguagem comunicativa do mundo da vida e vice-versa, o que possibilidade,
por exemplo, que as reivindicações do mundo da vida, expressas comunicativamente, como a
proteção da esfera privada contra disfunções ocasionadas pelos sistemas sociais ou a
preservação do meio ambiente, possam ser promulgadas na forma de leis que os agentes
envolvidos com os sistemas sociais têm que levar em consideração para realizar a escolha
racional da melhor estratégia de ação a partir da lógica própria de cada sistema. (2006, p.105)

Interessa frisar, entretanto, que, mesmo estando o direito na condição de intermediador entre os subsistemas e o mundo da vida, "o teórico do direito não pode reclamar para si nenhuma posição privilegiada" (PINZANI, 2009, p.143), porque não deixa de estar na posição de participante do mundo da vida devendo a isso sua posição hermenêutica. Isso, à evidência, aplica-se ao cientista social:

O agir social recebe seu sentido, então, do mundo da vida, no qual se encontram os atores assim como o observador, isto é, o cientista social. As ciências sociais enquanto ciências interpretativas estão presas em um círculo hermenêutico: elas não podem fugir do mundo da vida na qual o próprio observador se encontra. O mundo da vida constitui o horizonte no qual não somente se dá o objeto de tais ciências, a saber, o agir social, mas também acontecem as análises delas. (PINZANI, 2009, p.108)

\section{JUSTIÇA E DIFERENÇA: ELEMENTOS DE LINGUAGEM E FILOSOFIA DO DIREITO EM DERRIDA}

A nosso ver, seria muito pretensioso de nossa parte sintetizar as linhas mestras do pensamento de Derrida nas poucas páginas que se seguem. Com efeito, iremos nos circunscrever a dois trabalhos específicos: 1- a Gramatologia ${ }^{1}$ que nos permitirá trabalhar questões de filosofia da linguagem; 2- a

\footnotetext{
${ }^{1}$ Recentemente, devido aos acontecimentos do famoso caso Sokal, muitas obras de autores pós-estruturalistas (como Derrida) têm sido desacreditadas por, muitas vezes, apresentarem uma linguagem, por assim dizer, "abstrusa", beirando à falta de sentido.
} 
coletânea Força de lei (DERRIDA, 2010) que usaremos, principalmente, para trabalhar questões de filosofia do direito.

Começando, pois, pela filosofia da linguagem, devemos de saída afirmar que um dos principais (senão o principal) objetivo do pensamento de Derrida (naquilo que concerne à linguagem) consiste em estabelecer uma crítica àquilo que o filosofo francês denomina "a metafísica da presença" (cf DERRIDA, 2011, p.368-369); essa noção, longe de remeter diretamente a alguma das definições mais clássicas de metafísica, almeja, antes de qualquer coisa, remeter a uma ilusão que, vinda de uma má compreensão da linguagem, infiltrou-se em boa parte do pensamento ocidental.

Em sua busca por combater essa má compreensão da linguagem, Derrida na Gramatologia faz rigoroso estudo crítico de um tratado póstumo de Rosseau em que este tentaria refletir a respeito da linguagem. Analisando Rosseau, Derrida procura demonstrar os problemas nos quais o filósofo suíço, sem perceber, incide por pensar a linguagem sob a égide da "metafísica da presença". ${ }^{2}$

Mas o que seria essa metafísica da presença? Para Derrida, a metafísica da presença seria um tipo de pensamento que cai nas armadilhas de uma dualidade inexorável: a dualidade significadosignificante. De onde viria essa dualidade? A dualidade viria de um fato óbvio, porém, nem sempre percebido: ao se representar o mundo por intermédio da linguagem, está, desde já, pressuposta a distância entre a linguagem e o mundo. Noutros termos, apenas se pode dizer que se representa o mundo quando aberta está a possibilidade para que a representação possa ser ruim (falsa, imprópria etc) ou boa (bela, correta, verdadeira etc), e, por outro lado, só conseguimos distinguir os objetos da representação quando nos distanciamos deles ao tentarmos representá-los. Isso fica mais claro ao pensarmos em um exemplo: quando tentamos representar o mundo (o real, o Ser, o universo e etc.) podemos parar para pensar e constatar que tal mundo não é verdadeiro nem falso, visto que são as representações do mundo que são verdadeiras ou falsas; por outro lado, só distinguimos a própria existência do mundo (o real, o Ser, o universo e etc.) quando, ao tentarmos representá-lo, passamos a tratá-lo como um objeto (um ideal) a ser atingido por um mecanismo de representação (como um objeto externo à linguagem e ao qual devemos tentar atingir através de tal linguagem).

\footnotetext{
Esse tipo de característica "abstrusa”, a nosso ver, não está na Gramatologia, porquanto, ainda que admitíssemos ser o primeiro grande movimento dessa obra demasiado complexo e quase ininteligível, temos de admitir que, no segundo grande movimento, o autor repete boa parte das idéias postas no início sob a perspectiva de um claro e rigoroso trabalho historiográfico sobre as obras de Rosseau. Inclusive, para gerar o mínimo de polêmica, procuraremos nos ater a esse segundo movimento da obra.

${ }^{2}$ Ao dirigir esse tipo de crítica, Derrida pretende que Rosseau deva ser visto como sendo apenas um exemplo de uma série de erros que, ao longo de boa parte da história da filosofia (pelo menos, até Heidegger), estariam presentes. Não iremos, aqui, desenvolver essa postura de Derrida, tampouco expor o tipo de justificativa que, implícita ou explicitamente, o filosofo francês utiliza para eleger Rosseau como foco de sua percuciente análise.

Essa nossa decisão deve-se tanto à brevidade do espaço deste artigo, quanto ao fato de que o objetivo deste trabalho é antes estabelecer um diálogo entre dois autores (Habermas e Derrida), do que tomar um posicionamento a respeito da validade, ou não, do pensamento desses autores.
} 
A essa dualidade presente no coração da linguagem e da representação, Derrida dá o nome de différance $^{3}$; a différance, para Derrida, é a prova de que nunca poderemos atingir ideais de unidade como "Deus", “O Ser", “A natureza” etc. ${ }^{4}$ Esses ideais só podem ser pensados enquanto pares da dualidade primordial (différance), notando-se que, mesmo sem perceber, fazemos confusões e caímos em paradoxos. Um exemplo gritante dessa situação, na leitura de Derrida, está em Rosseau (cf, por exemplo, DERRIDA, 2011, p.378-379): tanto em sua reflexão a respeito da linguagem, quanto em outras reflexões, Rosseau (segundo Derrida) procura, ao mesmo tempo, elogiar uma espécie de instância metafísica primordial (a Natureza) e criticar tudo que nos afasta de tal instância (a sociedade, a linguagem etc); o problema aí, com o qual Rosseau parece se debater, é que, ao mesmo tempo em que se define a natureza por oposição a seus "inimigos" (a sociedade, a linguagem etc), tenta-se dizer que a natureza é o que há de mais primordial (de onde, paradoxalmente, inimigos como a sociedade e a linguagem teriam de ter surgido). Como conciliar essa situação? Para Derrida, qualquer tipo de conciliação é impossível, pois Rosseau descobre, no par "sociedade-natureza", a différance e, ao mesmo tempo, tenta contornar tal différance concedendo prioridade à natureza.

Vemos, nesse contexto, o caráter constrangedor da filosofia antimetafísica de Derrida. Isso significa que estamos presos em uma espécie de maldição da différance? Não, e é aí que entramos no ponto, por assim dizer, filosófico-jurídico deste texto: libertos da metafísica, podemos utilizar a différance como instrumento crítico e perceber que a metafísica pode, também, ocultar algo de nefasto. Um exemplo disso encontra-se, principalmente, no primeiro e no terceiro textos de Força de lei. Tais textos, de fato, possuem algo de obscuro, mas, com uma boa leitura prévia da Gramatologia, podem, a nosso ver, ser bem compreendidos: no Post-scriptum a Prenome de Benjamin, Derrida, a partir da interpretação que havia feito de um texto de Benjamin, investe contra a crítica benjaminiana segundo a qual o direito seria ilegítimo, pois seria fundado sobre uma violência primeira que, por ser anterior ao próprio direito (e sua condição de possibilidade), jamais poderia ter a própria legitimidade jurídica; em Do direito à justiça, Derrida, de modo mais claro, expõe aquilo que poderia se aproximar de uma filosofia do direito baseada no conceito de différance, notando-se que a principal característica dessa filosofia do direito derridiana seria pensar a lei como envolvida na inexorável dualidade da significação

\footnotetext{
${ }^{3} \mathrm{Na}$ tradução da Gramatologia que estamos utilizando, o termo é traduzido através do neologismo diferência . Há, no entanto, quem prefira usar outros neologismos (como diferança) de modo que, para evitar polêmica, optamos, aqui, por não traduzir o termo.

${ }^{4}$ Vale chamar a atenção para o fato de que, ao que parece, devamos ter cuidado para não tratar a própria différance como um ideal metafísico: se pararmos para pensar, veremos que sequer se deve falar muito a respeito da différance, pois esta representa a própria dualidade e quando tentamos falar dela, fatalmente, tratamo-la como um objeto de representação e, conseqüentemente, como um dos termos da dualidade a que ela deveria remeter.

Esse caráter complexo da différance talvez seja o motivo pelo qual, como ressalta Rorty (1991), Derrida, conforme sua obra evolui, foi aos poucos abandonando, cada vez mais, a tentativa de oferecer qualquer versão demasiado sistemática de sua filosofia.
} 
de modo que o papel do filósofo (cf DERRIDA, 2010, p.27-28) seria o de propor uma crítica constante em que se mostrasse a irredutível différance entre a lei (a representação) e a justiça (aquilo que se pretende representar com a lei).

Em que sentido esses dois textos (o Post-scriptum e Do direito à justiça) nos permitem ver o caráter nocivo da "metafísica da presença" criticada por Derrida? Encetar uma resposta a tal pergunta implica admitir que, tal como havia feito com o caso de Rosseau em Gramatologia, Derrida, em Prenome de Benjamim, culmina por demonstrar que Benjamim acaba caindo em paradoxo similar ao do autor do Contrato social quando desconsidera a différrance inexorável entre o direito e a justiça. Para bem se compreender isso, convém sublinhar que Derrida mostra que o filosofo alemão (Benjamim), ao se deparar com o fato de que o direito não pode se furtar a uma violência que o funda, é forçado a buscar a legitimidade do direito em uma justiça essencial que se oporia ao direito (na arbitrariedade violenta que o funda) da mesma maneira que instâncias como a linguagem e a sociedade se oporiam natureza de Rosseau. O problema dessa situação é que, segundo Derrida, ao abrir mão do direito enquanto instância representativa, Benjamim é forçado a recorrer à sua formação religiosa e invocar uma justiça divina. No entanto, a única forma de sustentar esse tipo de justiça é pensando que ela se manifesta na forma de catástrofes naturais. Benjamim, no final das contas, estaria substituindo um tipo de violência por outra; e isso se agrava quando, como faz Derrida no Post-scriptum, pensamos que a ideia de uma justiça divina que daria uma solução definitiva para o problema da justiça é (uma tal ideia) muito similar à postura de regimes totalitários que, como o nazismo, buscaram, em algum tipo de ufanismo patriótico, uma solução definitiva. ${ }^{5}$ Contra esse tipo de postura (quase fascista), Derrida, embora não dê uma solução, acaba, a nosso ver, deixando subentendida a postura de Do direito à justiça: a justiça, entendida como entidade metafísica definitiva, não existe. O que se pode fazer é tomar a justiça como uma espécie de polo oposto (no par significado-significante) ao direito (cf DERRIDA, 2010, p.41). Tal justiça, para uma filosofia da différrance, constituir-se-ia em algo que, além de impedir expedientes como o de Benjamim, permitiria um processo de reflexão crítica constante a respeito do direito.

\section{O FORA E O JURÍDICO: PONTES ENTRE UM TEÓRICO CRÍTICO E UM PÓS- ESTRUTURALISTA}

Gilles Deleuze defendia que começamos a pensar quando chegamos ao limite do nosso próprio pensamento. Isso pode parecer muito profundo, mas, na verdade, constitui-se em algo bastante simples.

\footnotetext{
${ }^{5}$ Nesse sentido, Derrida chama atenção para o fato de que um leitor de Benjamim poderia, facilmente, partir das posturas do autor (Benjamim) para concluir que, de alguma forma, o holocausto, ainda que não se concorde com as ideias que o embasam, foi um castigo divino. A esse respeito e de toda a crítica que Derrida faz a Benjamim, recomendamos, principalmente: Post-scriptum (DERRIDA, 2010, p.143-144).
} 
Não se trata de inserir, neste trabalho, a menção a um novo teórico ou a novas categorias filosóficas. Trata-se, na verdade, de se constatar o seguinte: começamos a pensar (nos questionar, raciocinar, pesquisar etc) quanto percebemos que não estamos compreendendo algo, ou não sabemos algo; pensamos para compreender ou aprender o não sabido, o desconhecido, o impensado.

Mas por que essa constatação nos é tão importante neste momento? Porque acreditamos que a relação entre Derrida e Habermas, naquilo que concerne ao pensamento da linguagem e do direito, manifesta, não obstante a divergência entre os dois autores, a característica comum de que ambos os autores estudados são descobridores da situação de que o direito encontra, devido a elementos decorrentes da própria filosofia da linguagem, limites que o levam, através de um diálogo com aquilo que lhe é externo (com seu fora), a manter uma situação de constante autocrítica: os limites decorrentes da filosofia da linguagem levam o direito a estar, constantemente, em uma busca por questionar (pensar) a si mesmo.

O que queremos dizer com tudo isso? Comecemos nos lembrando do que decorreu daquilo que trabalhamos a respeito de Derrida: o direito é a tentativa de representar a justiça e, no entanto, sempre deve se pensar em uma relação de exterioridade com relação a esta última; para verificar a validade de uma proposição jurídica (significante) pressupomos a justiça (significado) de modo que acabamos tendo de aceitar que esta última é algo externo ao direito. Por outro lado, só começamos a falar de justiça quando procuramos representá-la por algum meio (como o direito).

Com tudo isso, vivemos o inexorável paradoxo: pressupomos a justiça para avaliar o direito, e pressupomos o direito para trazer a justiça à luz; há certo distanciamento necessário entre direito e justiça de modo que o primeiro está sempre sujeito, por assim dizer, à justa crítica.

Essa proposta derridiana que procuramos detalhar em nosso segundo capítulo não deixa de ter algumas similaridades bastante interessantes com o pensamento habermasiano estudado em nosso primeiro capítulo. Com certeza Habermas não parte de uma reflexão sobre a significação similar à de Derrida, pois seu pensamento (o de Habermas) baseia-se em uma visão pragmática da linguagem ${ }^{6}$. Apesar desse posicionamento de Habermas (que difere do de Derrida), vemos que o filosofo alemão chega a um tipo de conclusão bastante similar àquela do filósofo francês: o direito precisa pensar-se em constante autocrítica, pois ele (o direito) encontra-se em meio a uma tensão entre facticidade e validade gerada pela situação de que as comunidades linguísticas geram valores morais (validade) que estão sempre ameaçados pelos fatos produzidos pelo pensamento técno-científico ${ }^{7}$. Em meio a essa

\footnotetext{
${ }^{6}$ Trata-se de algo próximo (senão idêntico) ao que poderíamos chamar de "fillosofia da linguagem ordinária" cuja referência, a nosso ver, ficou explícita quando, no primeiro capítulo, fez-se menção a noções como "comunidade de falantes" e "formas de vida".

${ }^{7}$ Aqui nos referimos, especificamente, àquela instância que, em nosso primeiro capítulo, foi referida com a palavra sistemas.
} 
situação de tensão, o direito é sempre forçado a manter-se em autocrítica: o direito deve, por assim dizer, viver em um movimento pendular em que, ora se deixa conduzir pelos sistemas (ciência, técnica, movimentos da grande economia etc), ora se deixa conduzir pelas comunidades linguísticas (formas de vida) e seus valores; cabe assim, ao pensamento jurídico ter, a todo tempo, senso crítico suficiente para saber de que elemento deve aproximar-se (como manter uma equilibrada a complexa balança entre "sistemas" e "mundo da vida"?).

Tomando esse último raciocínio, como negar a similaridade entre muitas das ideias propostas por Habermas e por Derrida? A causa dos problemas habermasianos que acabamos de retomar não é outra senão a esfera da linguagem: são os valores do "mundo da vida" (espaço das comunidades linguísticas) que são condição de possibilidade da tensão entre tal "mundo da vida" e os "sistemas". Se olharmos com atenção essa situação veremos que o pensamento de Habermas, tal como o de Derrida, depara-se com as complexas relações entre a linguagem e aquilo que lhe é externo, e, consequentemente, permite se pensar a difícil relação entre o direito e aquilo que lhe é alheio.

\section{CONSIDERAÇÕES FINAIS: DIFERENÇA E FACTICIDADE}

Vimos que, além da oposição que já é rotineira (como mostra o texto de Dutra, 2013), Habermas e Derrida possuem algumas proximidades. Para alguns, a percepção dessas similaridades, do modo como a empreendemos, poderia parecer mero exercício de futilidade: poder-se-ia alegar que a concepção do direito como autocrítico e das complexas relações entre a linguagem e aquilo que lhe é externo são, do ponto de vista do pensamento do século XX, um fato tão genérico que não faria sentido aproximar dois autores específicos através dele.

À parte essa possível objeção, invocando algo que dissemos na introdução, defenderemos aqui a validade de nosso texto: não é preciso passar muito tempo nas academias de filosofia para se perceber, principalmente no campo da filosofia contemporânea, o quão vorazes são as disputas entre autores, discípulos de autores e tendências filosóficas. Acreditamos que tentativas como a feita neste trabalho são propostas válidas permitem o historiador da filosofia contribuir com seu tempo, lembrando aos representantes das divergências filosóficas que, não obstante suas divergências, os diversos autores da filosofia contemporânea possuem, também, projetos em comum. Prestar a atenção a essa comunidade de projetos (como é o caso daquilo que mostramos ser comum entre Habermas e Derrida) pode, talvez, permitir que, em um futuro próximo, as diversas doutrinas e autores possam se focar mais à complementação mútua, do que à guerra teórica. 


\section{REFERÊNCIAS}

BANNWART JÚNIOR. Clodomiro José. Estruturas normativas da teoria da evolução social de Habermas. 2008. 265p. Tese (Doutorado em Filosofia). Universidade Estadual de Campinas (UNICAMP). Campinas.

DERRIDA, J. Gramatologia. São Paulo: Perspectiva, 2011. . Força de Lei. São Paulo: Martins fontes, 2010.

DURÃO, Aylton Barbieri. A tensão entre faticidade e validade no direito segundo Habermas. Ethic@, Florianópolis, v.5, n.1, p. 103-120, Jun. 2006.

DUTRA, D, J, V. Direito poder e violência: Habermas x Derrida. Disponível em: http://www.ufpel.edu.br/isp/dissertatio/revistas/antigas/dissertatio19-20.pdf. Consulta realizada em 02/09/2013.

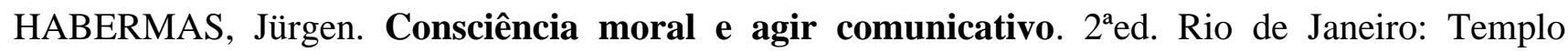
brasileiro, 2003. 1997.

. Direito e democracia: entre facticidade e validade. Vol.I. Rio de Janeiro: Templo brasileiro,

. Técnica e ciência como "ideologia". In: HABERMAS, Jürgen. Técnica e ciência como “ideologia". Lisboa: Edições 70, 1968. pp.45-92.

PINZANI, Alessandro. Habermas. Porto Alegre: Artmed, 2009. 